\title{
STRATEGI PENGEMBANGAN USAHA TANI KOPI ARABIKA (STUDI KASUS DI DESA GUNUNGSARI, KECAMATAN SUKANAGARA KABUPATEN CIANJUR)
}

\author{
Oleh : \\ Asep Saepul Alam**) \\ Marthen Cawer*)
}

\begin{abstract}
Abstrak
Untuk mengetahui lebih dalam tentang strategi pengembangan Usahatani Kopi Arabika Di Desa Gunungsari Kecamatan Sukanagara Kabupaten Cianjur, dilakukan penelitian. Tujuan penelitian ini adalah: 1. Untuk mengkaji Faktor-faktor strategis apa saja yang menjadi kekuatan, kelemahan, peluang, dan ancaman bagi Kelompok Tani Agro Mandiri Desa Gunungsari Kecamatan Sukanagara Kabupaten Cianjur jika dilihat dari aspek eksternal dan aspek internal serta 2. Strategi apa yang tepat untuk pengembangan usahatani kopi arabika Kelompok Tani Agro Mandiri Desa Gunungsari Kecamatan Sukanagara Kabupaten Cianjur. Waktu penelitian dilakukan selama bulan Januari 2019 sampai dengan bulan Mei 2019. Penarikan sampel dalam penelitian menggunakan non probality sampling, dimana pemilihan responden dipilih dengan tujuan tertentu. Responden yang diambil dalam penelitian ini berjumlah delapan orang. Analisis data terdiri dari analisis deskriptif dan analisis tiga tahap formulasi strategi. Alat bantu analisis yang digunakan untuk merumuskan strategi adalah matriks IFE, Matriks EFE, Matriks IE, matriks SWOT dan Matriks QSPM. Berdasarkan hasil analisis SWOT, yang dihasilkan, dimana prioritas strategi yang dipilih tersebut adalah : 1. Meningkatkan Produksi Kopi dengan memanfaatkan ketersediaan lahan yang cukup dan SDM yang terampil. 2. Mempertahankan keunggulan produk kopi dan memenuhi kebutuhan peminat kopi yang semakin meningkat 3. Memaksimalkan pengolahan lahan kopi melalui kerja sama dengan dinas pertanian dan perkebunan guna mendapatkan pelatihan. 4. Memanfaatkan keunggulan sumber daya (manusia, alam, mesin,) untuk meraih peluang. Diurutkan dengan menggunakan matriks QSPM. Adapun urutan prioritas strategi yang memiliki skor lebih tinggi dari alternatif lainnya untuk mengembangkan usaha tani kopi arabika di Kelompok Tani Agro Mandiri yaitu memanfaatkan keunggulan sumber daya (manusia, alam, mesin) untuk meraih peluang dengan nilai Total Attractiveness Score (TAS) sebesar 6,627.
\end{abstract}

Kata Kunci : Strategi Pengembangan QSPM, Kopi Arabika.

\begin{abstract}
Abstrac
To find out more about the strategy for developing Arabica Coffee Farming in Gunungsari Village, Sukanagara District, Cianjur Regency, a study was conducted. The purpose of this study is what : 1 . Strategic factors are the strengths, weaknesses, opportunities, and threats for the Agro Mandiri Farmers Group in Gunungsari Village, Sukanagara District, Cianjur Regency when viewed from the external and internal aspects as well as what 2. Strategies are appropriate for developing Arabica coffee farming. Agro Mandiri Farmers in Gunungsari Village, Sukanagara District, Cianjur Regency. The time of the study was carried out during January 2019 until May 2019. Sampling in the study used non probality sampling, where the selection of respondents was chosen with a specific purpose. Respondents taken in this study amounted to eight people. Data analysis consisted of descriptive analysis and three-stage analysis of strategy formulations. The analytical tool used to formulate the strategy is the IFE matrix, EFE Matrix, IE Matrix, SWOT
\end{abstract}


matrix and QSPM Matrix. Based on the results of the SWOT analysis, produced, where the chosen strategic priorities are: 1. Increase Coffee Production by utilizing the availability of sufficient land and skilled buman resources. 2. Maintaining the superiority of coffee products and meeting the growing needs of coffee enthusiasts 3. Maximizing the processing of coffee fields through collaboration with the agriculture and plantation offices to receive training. 4. Utilizing the advantages of resources (buman, natural, machine,) to seize opportunities. Sort by using the QSPM matrix. The priority order of the strategy that has a higher score than other alternatives to develop Arabica coffee farming in the Agro Mandiri Farmers Group is to utilize the advantages of resources (buman, natural, and machine) to seize opportunities with a Total Attractiveness Score (TAS) of 6.627 .

Keywords : Strategy Development QSPM, Arabica Coffee.

*) Alumni Fakultas Sains Terapan UNSUR

**) Dosen Fakultas Sains Terapan UNSUR 


\section{PENDAHULUAN}

Kopi merupakan komoditas perkebunan unggulan yang telah banyak dibudidayakan oleh berbagai Negara termasuk Indonesia. Sebagai komoditas penting, bahkan pernah dikatakan sebagai "komoditas kedua yang paling berharga yang diekspor oleh negara-negara berkembang" di buku tahunan komoditas dari konferensi PBB mengenai perdagangan dan pembangunan periode 1970-1998, kopi telah diperdagangkan di pasar komoditas dan Exchanged Traded Fund (ETF). International Coffee Organization (ICO) tahun 2015.

Menururt Dinas perkebunan Jawa Barat tahun 2015 kopi yang dihasilkan di Jawa Barat dikenal dengan nama kopi Arabica Java Preanger yang sudah terkenal ke seantero dunia sejak abad 18. Kopi tersebut memiliki rasa yang khas, gurih, lembut, bulat dan tidak membosankan. Dengan demikian, kopi tersebut selalu dicari oleh para penikmat dan pecinta kopi dunia.

Kabupaten Cianjur merupakan salah satu kabupaten yang termasuk dalam pengembangan Kawasan Agropolitan Kopi Jawa Barat. Komoditas perkebunan yang strategis dan juga yang sangat potensial untuk dikembangkan. Hingga saat ini pengelolaan kopi di Kabupaten Cianjur masih tergolong sederhana. Masih banyak yang perlu diperbaiki dalam pengelolaan kopi Cianjur. Dari segi produktifitas, Kabupaten Cianjur masih belum sanggup menghasilkan kopi sebanyak 1 ton per hektar, bahkan kalah dibandingkan dengan Kabupaten Sukabumi yang sudah mampu menghasilkan kopi sebanyak 1.03 ton per hektar.

Program pengembangan Kawasan Agropolitan Jabal Talun Kabupaten Cianjur (KAJTKC), membawa harapan akan terwujudnya pengembangan potensi komoditas pertanian Kabupaten Cianjur, khususnya potensi kopi untuk mendongkrak perekonomian dan pembangunan serta mensejahterakan penduduk petani kopi Kabupaten Cianjur.
Para petani masih menghadapi keterbatasan akses informasi teknologi budidaya dan pascapanen kopi, keterbatasan modal, rendahnya inovasi untuk pengemasan produk dan jaringan pemasaran; terbatasnya jumlah petani yang memiliki pengetahuan dan keterampilan untuk mengolah kopi secara benar dan tepat sesuai standar operasional prosedur.Permasalahan-permasalahan yang dihadapi oleh petani kopi di Desa Gunungsari memerlukan strategi pemecahan masalah yang tepat untuk pengembangan kopi di desa Gunungsari. Oleh sebab itu, menarik untuk diteliti lebih lanjut mengenai bagaimana "Strategi Pengembangan Usahatani Kopi Arabika" (Studi Kasus di Desa Gunungsari, Kecamatan Sukanagara, Kabupaten Cianjur).

Mengacu pada permasalahan yang hendak di teliti maka tujuan penelitian ini adalah sebagai berikut:

1. Untuk menganalisis faktor-faktor internal dan eksternal yang dimiliki petani dalam usaha pengembangan usahatani kopi Cianjur didaerah penelitian.

2. Untuk menganalisis strategi pengembangan usahatani yang dapat dilakukan didaerah penelitian.

\section{METODE PENELITIAN}

Lokasi penelitian dilakukan di Desa Gunungsari Kecamatan Sukanagara Kabupaten Cianjur Selatan. Pemilihan daerah penelitian ini dilakukan dengan sengaja (purposive) dengan beberapa pertimbangan. Pertimbangan pertama Desa Gunungsari adalah salah satu Desa penghasil kopi di Sukanagara Kabupaten Cianjur. Pertimbangan kedua. Desa Gunungsari mempunyai potensi sumberdaya alam khususnya lahan pertanian yang subur, sumberdaya manusia yang memiliki semangat, kerja keras dan budaya bertani yang turun temurun. Penelitian ini dilaksankan dengan mengunakan data primer dan data sekunder yaitu di Desa Gunungsari, Kecamatan Sukanagara Kabupaten 
Cianjur Selatan. Data dan informasi yang dibutuhkan berupa data primer dan data sekunder. Pengumpulan data primer diperoleh dari suvei lapangan dan wawancara. Survei lapangan dengan penyebaran kuesioner. Penentuan sampel dilakuan dengan cara purpusive sampling/non probolity sampling, besar sampel yang digunakan 8 orang responden, 5 orang internal dan 3 ornag eksternal. Analisis data yang digunakan dalam kajian ini adalah 1. Analisis Deskretif kualitatif. 2. Analisis Matriks IFE (Internal Factor Evalution) dan EFE ( Eksternal Factor Evalution). 4 Analisis Matriks SWOT ( Strengths, Weaknesses, Oppurtunities, and Threats). 5 Analisis Matriks QSPM (Quantitative Strategic Planning Matrix).

\section{HASIL DAN PEMBAHASAN PENELITIAN}

\section{Faktor - Faktor Internal (Kekuatan dan Kelemahan)}

Berdasarkan hasil penelitian lingkungan internal pada Kelompok Tani Agro Mandiri Desa Gunungsari Kecamatan Sukanagara Kabupaten Cianjur, maka diperoleh faktor strategi internal yang berupa kekuatan dan kelemahan. Adapun faktor-faktor strategi internal sebagai berikut:

\section{Kekuatan (Strengths)}

a. Terdapat sumber daya alam yang sesuai

b. Mempunyai lahan produksi sendiri

c. Keuntungan maksimal

d. Ketersediaan lahan yang cukup besar

e. Sumber daya manusia yang terampil dalam mengusahakan produksi kopi

f. Adanya mesin pengolahan kopi dapat mempercepat produksi kopi yang baik

g. Banyaknya peminat kopi arabika Kelompok Tani Agro Mandiri

\section{Kelemahan (weaknesses)}

a. Kurangnya perawatan mesin untuk memproduksi kopi

b. Membutuhkan waktu yang cukup lama c. Pengolahan lahan pertanian kopi yang kurang maksimal mengakibtakan kurangnya produktifitasanya

d. Kurangnya konsisten petani kopi

e. Keterbatasan jumlah buruh tani akan mengakibatkan turunnya jumlah kinerja buruh tani.

\section{Faktor - Faktot Eksternal (Peluang dan Ancaman)}

Berdasarkan hasil penelitian lingkungan eksternal pada kopi arabika Kelompok Tani Agro Mandiri Desa Gunungsari Kecamatan Sukanagara Kabupaten Cianjur, maka diperoleh beberapa faktor strategi yang berupa peluang dan ancaman. Adapun faktorfaktor strategi eksternal adalah sebagai berikut:

\section{Peluang (Opportunities)}

a. Mulai tumbuh organisasi kopi di Cianjur

b. Dinas Pertanian dan Perkebunan memberikan pelatihan kepada masyarakat diwilayah Cianjur

c. Perkembangan teknologi, informasi dan komunikasi

d. Ada kecenderungan semakin banyak menyukai kopi

e. Pasar yang masih terbuka baik domestik maupung luar negeri

f. Budaya minum kopi menjadi peluang pengembangan kopi

g. Pemasaran kopi bersertifikat bisa menduania

h. Keunggulan produk kopi

\section{Ancaman (Threats)}

a. Persaingan produk kopi yang meningkat dari luar Cianjur

b. Pemerintah Cianjur kurang menciptakan kerjasama terhadap stakeholder

c. Karena kopi merupakan produk universal maka kegiatan eksporimpor sangat dipengaruhi keadaan politik suatu negara

d. Bertumbuh peluang yang tidak pasti

e. Masuknya ragam kopi dari luar negeri

f. Pertumbuhan ekonomi 
g. Teknik pasca panen dan pemasaran

Faktor-faktor tersebut di atas dihasilkan dari hasil wawancara secara langsung dengan sejumlah responden diantaranya ketua Kelompok Tani Agro Mandiri, Anggota Kelompok Tani, bidang akademisi dan para penyuluh kopi di Cianjur.

\section{Analisis Matriks IFE (Internal Factor Evalution)}

Tabel 1. Hasil Analisis Matrix IFE Kopi Arabika Perkumpulan di Kelompok Tani Agro Mandiri.

\begin{tabular}{|c|c|c|c|c|}
\hline & $\begin{array}{c}\text { FAKTOR-FAKTOR STRATEGIS } \\
\text { INTERNAL } \\
\text { KEKUATAN } \\
\end{array}$ & $\begin{array}{l}\text { BOBOT } \\
\text { RATA- } \\
\text { RATA }\end{array}$ & $\begin{array}{l}\text { RATING } \\
\text { RATA- } \\
\text { RATA }\end{array}$ & $\begin{array}{c}\text { BOBOT } \\
\text { SKOR } \\
\text { RATA-RATA }\end{array}$ \\
\hline A & Terdapat sumber daya alam yang sesuai & 0,083 & 3,6 & 0,299 \\
\hline B & Mempunyai lahan produksi sendiri & 0,082 & 3,9 & 0,318 \\
\hline $\mathrm{C}$ & Keuntungan maksimal & 0,088 & 3,4 & 0,297 \\
\hline $\mathrm{D}$ & Ketersediaan lahan yang cukup besar & 0,087 & 3,9 & 0,339 \\
\hline $\mathrm{E}$ & $\begin{array}{l}\text { Sumber daya manusia yang terampil dalam } \\
\text { mengusahakan produksi kopi }\end{array}$ & 0,083 & 3,8 & 0,310 \\
\hline $\mathrm{F}$ & $\begin{array}{l}\text { Adanya mesin pengolahan kopi dapat } \\
\text { mempercepat produksi yang baik }\end{array}$ & 0,088 & 3,3 & 0,286 \\
\hline G & $\begin{array}{l}\text { Banyaknya peminat kopi arabika kelompok } \\
\text { tani agro mandiri }\end{array}$ & 0,086 & 3,8 & 0,321 \\
\hline \multicolumn{2}{|r|}{ KELEMAHAN } & & JUMLAH & 2,171 \\
\hline $\mathrm{H}$ & $\begin{array}{l}\text { Kurangnya perawatan mesin untuk } \\
\text { memproduksi kopi }\end{array}$ & 0,081 & 1,5 & 0,122 \\
\hline I & Membutuhkan waktu yang cukup lama & 0,079 & 1,8 & 0,139 \\
\hline $\mathrm{J}$ & $\begin{array}{l}\text { Pengolahan lahan pertanian kopi yang kurang } \\
\text { maksimal mengakibatkan kurangnya } \\
\text { produktifitasnya }\end{array}$ & 0,086 & 1,6 & 0,140 \\
\hline K & Kurangnya konsisten petani kopi & 0,080 & 1,6 & 0,131 \\
\hline $\mathrm{L}$ & $\begin{array}{l}\text { Keterbatasan jumlah buruh tani akan } \\
\text { mengakibatkan turunnya jumlah kinerja } \\
\text { buruh tani }\end{array}$ & 0,076 & 1,8 & 0,134 \\
\hline \multicolumn{4}{|c|}{ JUMLAH } & 0,665 \\
\hline \multicolumn{4}{|c|}{ JUMLAH TOTAL } & 2,836 \\
\hline
\end{tabular}

Sumber: Data Primer diolah, 2019.

Tabel 4.1 Menujukkan faktor strategi internal apa yang menjadi kekuatan dan kelemahan utama atau besar (mayor) bagi kopi arabika Kelompok Tani Agro Mandiri. Adapun kekuatan besar (mayor) bagi kopi arabika Kelompok Tani Agro Mandiri adalah memiliki organisasi yang jelas dengan skor bobot rata-rata
0,339. Secara keseluruhan total skor ratarata terhitung dari matrix IFE 2,836. yang mengindikasikan bahwa kondisi internal kopi arabika Kelompok Tani Agro Mandiri berada disekitar rata-rata (2,02,99) atau sedang. dari keseluruhan kekuatan internal. 


\section{Analisis matrix EFE ( Eksternal Factor Evalution)}

Tabel 2. Hasil Analisis Matrix EFE Kopi Arabika di Kelompok Tani Agro Mandiri.

\begin{tabular}{|c|c|c|c|c|}
\hline & $\begin{array}{c}\text { FAKTOR-FAKTOR STRATEGIS } \\
\text { EKSTERNAL } \\
\text { PELUANG }\end{array}$ & $\begin{array}{l}\text { RATA- } \\
\text { RATA } \\
\text { BOBOT }\end{array}$ & $\begin{array}{l}\text { RATA- } \\
\text { RATA } \\
\text { RATING }\end{array}$ & $\begin{array}{l}\text { RATA- } \\
\text { RATA } \\
\text { SKOR }\end{array}$ \\
\hline A & Mulai tumbuh organisasi kopi di Cianjur & 0,071 & 3,6 & 0,259 \\
\hline B & $\begin{array}{l}\text { Dinas pertanian dan perkebunan memberikan } \\
\text { pelatihan kepada masyarakat di wilayah } \\
\text { Cianjur }\end{array}$ & 0,063 & 3,4 & 0,211 \\
\hline $\mathrm{C}$ & $\begin{array}{l}\text { Perkembangan teknologi, informasi dan } \\
\text { komunikasi }\end{array}$ & 0,071 & 3,3 & 0,231 \\
\hline $\mathrm{D}$ & Harga kopi yang terus menerus bertambah & 0,064 & 3,5 & 0,224 \\
\hline $\mathrm{E}$ & $\begin{array}{l}\text { Pasar yang masih terbuka baik domestik } \\
\text { maupun luar negeri }\end{array}$ & 0,074 & 3,4 & 0,251 \\
\hline $\mathrm{F}$ & $\begin{array}{l}\text { Ada kecenderungan semakin banyak menyukai } \\
\text { kopi }\end{array}$ & 0,061 & 3,8 & 0,227 \\
\hline G & Pemasaran kopi bersertifikat bisa mendunia & 0,070 & 3,9 & 0,273 \\
\hline $\mathrm{H}$ & Keunggulan produk kopi & 0,074 & 3,6 & 0,267 \\
\hline & ANCAMAN & & JUMLAH & 1,942 \\
\hline I & $\begin{array}{l}\text { Persaingan produk kopi yang meningkat dari } \\
\text { luar Cianjur }\end{array}$ & 0,066 & 1,9 & 0,124 \\
\hline $\mathrm{J}$ & $\begin{array}{l}\text { Pemerintah cianjur kurang menciptakan } \\
\text { kerjasama terhadap stakeholder }\end{array}$ & 0,058 & 2,0 & 0,116 \\
\hline K & $\begin{array}{l}\text { Karena kopi merupakan produk universal } \\
\text { maka kegiatan ekspor-impor sangat } \\
\text { dipengaruih keadaan politik suatu negara }\end{array}$ & 0,071 & 2,1 & 0,150 \\
\hline $\mathrm{L}$ & Bertumbuh peluang yang tidak pasti & 0,060 & 1,6 & 0,098 \\
\hline M & Masuknya ragam kopi dari luar negri & 0,065 & 2,0 & 0,130 \\
\hline $\mathrm{N}$ & Pertumbuhan ekonomi & 0,064 & 1,9 & 0,121 \\
\hline $\mathrm{O}$ & Teknik pasca panen dan pemasaran & 0,068 & 2,1 & 0,144 \\
\hline \multicolumn{4}{|c|}{ JUMLAH } & 0,883 \\
\hline \multicolumn{4}{|c|}{ JUMLAH TOTAL } & 2,825 \\
\hline
\end{tabular}

Sumber: Data Primer diolah, 2019.

Tabel 4.2 menunjukkan faktorfaktor strategi eksternal yang menjadi peluang dan ancaman bagi Kelompok Tani Agro Mandiri. Peluang utama bagi Kelompok Tani Agro Mandiri adalah variabel yang memiliki bobot skor ratarata terbesar, yaitu mulai tumbuh organisasi kopi di Cianjur dengan bobot skor rata-rata sebesar 0,273. Ancaman utama bagi Kelompok Tani Agro Mandiri adalah variabel yang memiliki bobot skor rata-rata terkecil, yaitu bertumbuh peluang yang tidak pasti dengan bobot skor ratarata sebesar 0,098. Adapun total skor ratarata tertimbang dari matriks EFE sebesar 2,825 yang mengindikasikan bahwa Kelompok Tani Agro Mandiri berada di sekitar rata-rata (2,00-2,99) yang memiliki posisi eksternal yang sedang dalam upayanya untuk menjalankan strategi yang memanfaatkan peluang dan menghindari ancaman. 


\section{Analisis Matrik IE (Internal Eksternal)}

Tabel 3. Hasil Analisis Matrik IE (Internal-Eksternal) Kopi Arabika di Kelompok Tani Agro Mandiri

\begin{tabular}{|c|c|c|c|c|}
\hline \multicolumn{2}{|c|}{ Eksternal } & \multicolumn{3}{|c|}{ Total Rata-Rata Pertimbangan IFE } \\
\hline \multirow{4}{*}{ 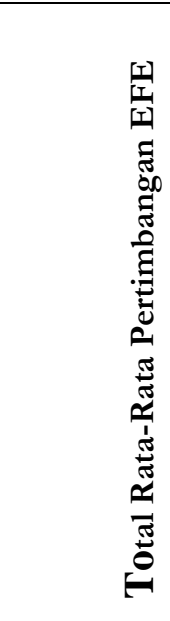 } & \multirow[b]{2}{*}{ 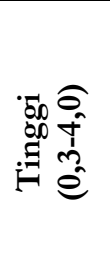 } & $\begin{array}{c}\text { Kuat } \\
(3,0-4,0)\end{array}$ & $\begin{array}{l}\text { Rata-rata } \\
(2,0-2,99)\end{array}$ & $\begin{array}{c}\text { Lemah } \\
(1,0-1,99)\end{array}$ \\
\hline & & $\mathrm{I}$ & II & III \\
\hline & 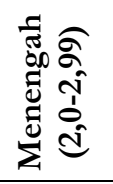 & IV & $\begin{array}{c}\text { EFE }(\mathbf{2 , 8 3 6}) \\
\mathrm{V}\end{array}$ & VI \\
\hline & 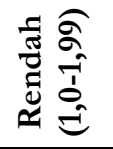 & VII & VIII & IX \\
\hline
\end{tabular}

Sumber: Data Primer diolah 2019.

Tabel 4.4 Menujukkan bahwa posisi kopi Arabika Kelompok Tani Agro Mandiri berada pada sel V, yaitu memiliki kemampuan internal yang sedang dan eksternal yang sedang. Organisasi seperti ini paling baik dikendalikan dengan strategi Hold and Maintain ( jaga dan pertahankan)

\section{Analisis Matriks SWOT ( Strengths, Weaknesses, Oppurtunities, and Threats)}

Tabel 4. Hasil Analisis matrik SWOT Kopi Arabika di Kelompok Tani Agro Mandiri.

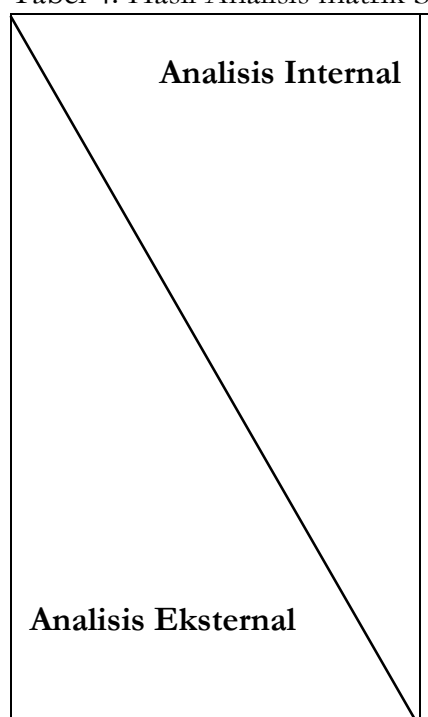

\section{KEKUATAN (S)}

A. Terdapat sumber daya alam yang sesuai

B. Mempunyai lahan produksi sendiri

C. Keuntungan maksimal

D. Ketersediaan lahan yang cukup besar

E. Sumber daya manusia yang terampil dalam mengusahakan produksi kopi

F. Adanya mesin pegolahan kopi dapat mempercepat produksi yang baik

G. Banyaknya peminat kopi arabika Kelompok Tani Agro Mandiri

\section{KELEMAHAN (W)}

A. Kuranganya perawatan mesin untuk memproduksi kopi

B. Membutuhkan waktu yang cukup lama

C. Pengolahan lahan pertanian kopi yang kurang maksimal mengakibatkan kurangnya produktifitasnya

D. Kurangnya konsisten petani kopi

E. Keterbatasan jumlah buruh tani akan mengakibtakan turunya jumlah kinerja buruh tani 


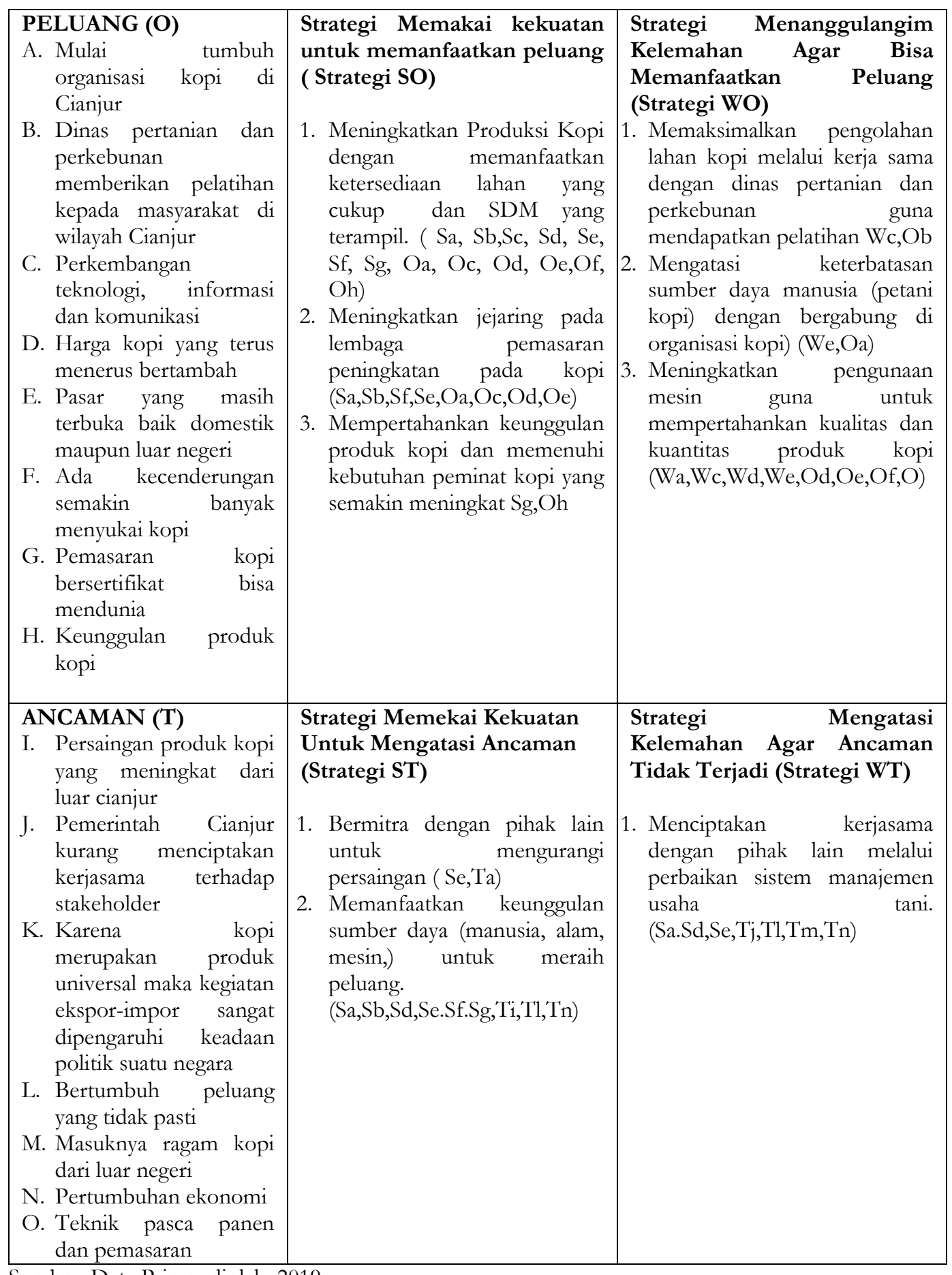

Sumber: Data Primer diolah, 2019. 


\section{Formulasi Strategi Tahap Keputusan (Decision Stage)}

Prioritas Alternatif Strategi Pada Pengembangan Kopi Arabika Kelompok Tani Agro Mandiri

\begin{tabular}{|c|c|c|c|c|c|c|c|c|c|c|}
\hline & $\begin{array}{c}\text { Responden } \\
1 \\
\end{array}$ & $\begin{array}{c}\text { Responden } \\
2 \\
\end{array}$ & $\begin{array}{c}\text { Responden } \\
3\end{array}$ & $\begin{array}{c}\text { Responden } \\
4\end{array}$ & $\begin{array}{c}\text { Responden } \\
5\end{array}$ & $\begin{array}{c}\text { Responden } \\
6\end{array}$ & $\begin{array}{c}\text { Responden } \\
7 \\
\end{array}$ & $\begin{array}{c}\text { Responden } \\
8 \\
\end{array}$ & $\begin{array}{c}\text { rata- } \\
\text { rata }\end{array}$ & $\begin{array}{l}\text { Prioritas } \\
\text { Strategi }\end{array}$ \\
\hline $\begin{array}{c}\text { STAS } \\
8\end{array}$ & 7,549 & 6,124 & 6,689 & 6,205 & 6,647 & 7,423 & 6,134 & 6,247 & 6,627 & 1 \\
\hline $\begin{array}{c}\text { STAS } \\
3\end{array}$ & 6,580 & 6,092 & 5,981 & 6,897 & 6,819 & 6,947 & 5,909 & 6,263 & 6,436 & 2 \\
\hline $\begin{array}{c}\text { STAS } \\
6\end{array}$ & 6,620 & 6,929 & 6,488 & 6,242 & 7,002 & 6,469 & 5,567 & 6,143 & 6,432 & 3 \\
\hline $\begin{array}{c}\text { STAS } \\
9\end{array}$ & 6,528 & 6,376 & 6,223 & 6,472 & 6,559 & 6,764 & 5,847 & 6,235 & 6,376 & 4 \\
\hline $\begin{array}{c}\text { STAS } \\
1\end{array}$ & 6,674 & 5,994 & 6,160 & 6,375 & 7,205 & 6,612 & 5,370 & 6,429 & 6,352 & 5 \\
\hline $\begin{array}{c}\text { STAS } \\
2\end{array}$ & 6,944 & 5,783 & 6,689 & 6,887 & 6,116 & 6,103 & 6,063 & 6,228 & 6,351 & 6 \\
\hline $\begin{array}{c}\text { STAS } \\
7\end{array}$ & 5,778 & 7,146 & 6,518 & 6,465 & 5,779 & 6,644 & 6,163 & 6,094 & 6,323 & 7 \\
\hline $\begin{array}{c}\text { STAS } \\
4\end{array}$ & 6,415 & 6,469 & 4,947 & 6,227 & 6,784 & 6,947 & 5,952 & 6,455 & 6,274 & 8 \\
\hline $\begin{array}{c}\text { STAS } \\
5\end{array}$ & 5,664 & 6,476 & 6,316 & 6,476 & 6,124 & 6,964 & 5,614 & 6,022 & 6,207 & 9 \\
\hline
\end{tabular}

Sumber: Data Primer diolah, 2019.

Berdasarkan hasil perhitungan STAS rata-rata pada tabel 4.5 maka prioritas strategi terbaik dari Sembilan adalah memanfaatkan keunggulan sumber daya (manusia,alam,mesin,) untuk meraih peluang. dengan STAS (Sum Total Attractiviness Scores) rata-rata sebesar 6,627 .

\section{KESIMPULAN}

Berdasarkan hasil analisis yang telah dilakukan pada Kelompok Tani Agro Mandiri dalam pengembangan kopi arabika, maka diperoleh beberapa kesimpulan yaitu :

1)Berdasarkan data-data yang diperoleh serta hasil analisis yang dilakukan terhadap Usaha Tani Kopi Arabika di Desa Gunungsari Kecamatan Sukanagara Kabupaten Cianjur yang meliputi analisis internal dan eksternal dalam usaha pengembangan usaha tani kopi arabika dengan faktor kekuatan bobot tertinggi yaitu 0,339 ketersediaan lahan yang cukup besar dan faktor kelemahan dengan bobot tertinggi yaitu 0,140 Pengolahan lahan pertanian kopi yang kurang masimal mengakibatkan kurangnya produktifitas. Faktor eksternal yang dihadapi petani kopi dalam mengembangkan usahatani kopi arabika adalah faktor peluang dengan bobot tertinggi yaitu 0,259 mulai tumbuh organisasi kopi di cianjur. Dan ancaman dengan bobot tertinggi yaitu 0,150 Karena kopi merupakan produk universal maka kegiatan ekspor-impor sangat dipengaruhi keadaan politik suatu negara.

2)Berdasarkan hasil analisis SWOT, yang dihasilkan sembilan strategi, dimana prioritas strategi tertinggi yang terpilih diurutkan dengan menggunakan matriks QSPM. Adapun urutan prioritas strategi yang memiliki skor lebih tinggi dari alternatif lainnya untuk mengembangkan usaha tani kopi arabika di Kelompok Tani Agro Mandiri yaitu 1. Memanfaatkan keunggulan sumber daya (manusia, alam, mesin) untuk meraih peluang dengan nilai Total Attractiveness Score (TAS) sebesar 6,627. 2. Mempertahankan keunggulan produk kopi dan memenuhi kebutuhan peminat kopi yang semakin meningkat. (STAS = 6,436). 3. Meningkatkan pengunaan mesin guna untuk mempertahankan kualitas dan kuantitas produk kopi. $($ STAS $=6,432)$. 


\section{DAFTAR PUSTAKA}

Aulia,Ilham.2012. Faktor - faktor yang mempengaruhi permintaan komodti kopi di sumatra Utara.Fakultas Pertanian. Universiitas Sumatra Utara.Sumatra Utara.

David, Fred R., 2011. Konsep Manajemen Strategi. Penerjemah Handy Hadi. Edisi VII Jakarta. Pershallindo.

Dinas Perkebunan Jawa Barat. 2016. Statistik Perkebunan Jawa Barat. Diperoleh Melalui Situs Internet: http://disbun.jabarprov.go.id/inde x. php/. Diunduh pada 1 Juli 1016).

Dyson, 2002. Strategi Development And SWOT Analysis At The University of Warwick. In Elsevier - European Juurnal Of Operation Research.

Fathul, H Muhammad 2010. Strategi Pemasaran Musyarakah. Yogyakarta. Baitul Maal Wal Tamwil Mandiri Ngaglik Sleman.

Fred. R. David. 2011, dalam Puspasari. dan Dedy. 2013. Matrik QSPM.

Griffin. 2010. Dan Ebert. Faktor Lingkungan Eksternal: Dalam Buku Herry Achmad Buchory Dan Djaslim Saladin. ( Edisi Ke-10 Jilid 3) Jakrata.

Indonesia Investment. (2011). Produksi Domestik, Ekspor Dan Konsumsi Kopi Indonesia. Diperoleh Melalui Situs: $\quad$ http://www.indonesiainvestments. com/id/bisnis/komoditas/kopi/. Pada 1 Juli 2016.Diunduh.

Interna sional Coffee Organization. 2015. World Coffee Consumption. http://www.ico.org/prices/poprod uction.pdf.

Mairiyansyah. 2014. Tingkat Motivasi Konsumen Kopi Arabika. Bogor : Klinik Kopi.

Pierce And Robinson 2010. Manajemen Strategi: Formulasi Implementasi Dan Pengendalian (Alih Bahsa Agus Maulana). Bina Rupa Aksara. Jakarta.
Santosa, 1999. Produktivitas Usaha Tani Kopi Rakyat. Bandung. PT Remaja Rosdakarya.

Saragih, Bungara. 2005. Kumpulan Agribisnis Paradikma Baru Pembangunan Ekonomi Berbasis Pertanian. Yayasan Mulia Persada Indonesia. Bogor.

Spillane, J.J.1990.Komoditi Kopi dan Peranannya Dalam Perekonomian Indonesia, Kanisius.Yogyakarta. 